\title{
Grid Loading due to EV Charging Profiles Based on Pseudo-Real Driving Pattern and User Behaviour
}

\author{
Calearo, Lisa; Thingvad, Andreas; Suzuki, Kenta; Marinelli, Mattia
}

Published in:

IEEE Transactions on Transportation Electrification

Link to article, DOI:

10.1109/TTE.2019.2921854

Publication date:

2019

Document Version

Peer reviewed version

Link back to DTU Orbit

Citation (APA):

Calearo, L., Thingvad, A., Suzuki, K., \& Marinelli, M. (2019). Grid Loading due to EV Charging Profiles Based on Pseudo-Real Driving Pattern and User Behaviour. IEEE Transactions on Transportation Electrification, 5(3), 683-694. https://doi.org/10.1109/TTE.2019.2921854

\section{General rights}

Copyright and moral rights for the publications made accessible in the public portal are retained by the authors and/or other copyright owners and it is a condition of accessing publications that users recognise and abide by the legal requirements associated with these rights.

- Users may download and print one copy of any publication from the public portal for the purpose of private study or research.

- You may not further distribute the material or use it for any profit-making activity or commercial gain

- You may freely distribute the URL identifying the publication in the public portal 


\title{
Grid Loading due to EV Charging Profiles Based on Pseudo-Real Driving Pattern and User Behaviour
}

\author{
Lisa Calearo, Student Member, IEEE, Andreas Thingvad, Student Member, IEEE, Kenta Suzuki, Mattia \\ Marinelli, Senior Member, IEEE
}

\begin{abstract}
This paper defines a method for generating individual electric vehicle charging patterns and it intends to quantify the realistic loading impact on distribution grid feeders.

The inputs are based on historical driving characteristics of private conventional vehicles from Denmark and home plug-in behavior of EVs from Japan. The first input is used to define properties such as the daily driven distance and the expected departure and arrival time, which determines the possible home charging window. The second input is used to quantify the probability of performing a domestic charge every day. Because most of the EVs does not need to charge every day, even when considering a $100 \% \mathrm{EV}$ penetration scenario, the amount of simultaneous charging with domestic single-phase charging power $(3.7 \mathrm{~kW})$ determines a coincidence factor lower than $45 \%$.

When considering three-phase charging $(11 \mathrm{~kW})$, the combined power of the $\mathrm{EV}$ population increases only to $50 \%$ because of shorter charging sessions. Although the power increase, due to 11 kW charging, is likely to trigger grid components overloading, it is highlighted how uncontrolled distribution of single-phase charging could be responsible for local voltage unbalances.
\end{abstract}

Index Terms-Power distribution, road vehicles, user modeling, battery chargers.

\section{INTRODUCTION}

The charging pattern of uncontrolled battery electric vehicles (EVs) is complicated to quantify due to the low amount of registered real cases and to the uncertainties factors related to individual driving behaviour, penetration level of EVs and charging power [1], [2]. On the other hand, system operators have to guarantee stability and security of supply, adapting the grid layout and the operation to the specific network characteristics and components [3]. To operate the grid with large penetrations of EVs, the system operators are interested in forecasting the EV charging load, to estimate impacts and necessities of infrastructure upgrades [4]-[6]. The load demand highly affects the quality of the power distribution [7], thus in literature different authors investigated the consequences of uncontrolled charging of the EVs [8]-[22]. These studies are based on a wide range of assumptions. In [8] all EVs are considered to be driven $32.7 \mathrm{~km}$ per day, in [9] all EVs are charged once a day after their last trip arrival time, in [10] all the EVs are plugged in with state-of-charge (SOC) of $30 \%$, in [11] the EVs are modelled with average daily driving distance of $53 \mathrm{~km}$ and the associated battery with 10

L. Calearo, A. Thingvad and M. Marinelli are with the Centre for Electric Power and Energy, Department of Electrical Engineering, Technical University of Denmark, Denmark. K. Suzuki is with the Nissan Motor Co., Ltd. Research Division EV System Laboratory. Yokosuka, Kanagawa, Japan. Corresponding author: M. Marinelli, Technical University of Denmark, Ris $\emptyset$ Campus, Frederiksborgvej 399, 4000 Roskilde, Denmark, (email: matm@elektro.dtu.dk), tel: +4520124369
$\mathrm{kWh}$ storage, in [12] $10 \%$ of EVs connected during the peak hours can inject power into the grid as vehicle-to-grid (V2G) support, in [13] the $37 \%$ EV penetration charges concurrently at 18:00. In [14]-[16] high EV penetrations (until 100\%) are considered, but even though the EVs are charged with different plug-in time during the evening hours, most of EVs get to charge simultaneously stressing the grid boundaries. Despite the variety of assumptions, the above studies result in a sharp consumption increase that can lead to severe voltage deviations and overloading conditions, where the acceptable share of uncontrolled charging EVs is approx. $30-50 \%$ penetration. The cited studies consider radial feeders, which present the worst scenario, as the cables in the beginning of the feeder have to carry the load of all the following ones [1], but also a realistic situation, as most distribution feeders are radially connected. For this reason to increase the penetration limit some studies analyzed the effect of different control strategies: for example, in [8] the Time of Use pricing was included, in [9] the authors focused on the minimization of the electrical charging payment of the customers, in [10] the demand management was investigated using two kinds of control: staggering the charging time of the EVs and performing household load control. In [12], to reduce the investment requirements during the peak hours, the authors moved the charging periods from peak to off-peak hours, whereas in [17] the interest was on the minimization of power losses. The aforementioned kinds of coordination succeed in diversifying the EV charging profiles, but customer driving and charging habits can be controlled only to a certain degree [23]. Furthermore, as investigate in [24]-[29], the EVs could be used to mitigate adverse effects and support the overall power system and distribution grid, for example with frequency regulation, voltage control, active power regulation etc.. All the previous works consider worst case of simultaneous charging, whereas in this paper, as in [30], [31], the authors investigate the historical data of gasoline cars, to derive more realistic and differentiated EV charging loads. Nevertheless in [30], [31] the authors consider EVs with a share of plug-in hybrid electric vehicles, resulting in a lower total electricity consumption. Furthermore, in most of the previous articles the considered share of EVs is charged on a daily basis or, in few cases, a low percentage of vehicles is charged every day based on authors' discretion, without providing any specific reason for the assumption. In a real situation it is expected that EV owners, which drive short distances per day, would charge fewer times than the ones that drive long distances [32]. Furthermore, the battery of the EV tends to age more whenever left at high values of SOC [33], thus a smart management of the EV would avoid filling 
up the vehicle at every possible occasion. The probability of charging is taken into consideration in this paper thanks to a Japanese analysis of Nissan EVs with EV data loggers, which provides the relationship between the plug-in ratio at home of EV drivers and the SOC. The Japanese study is based on $1000024 \mathrm{kWh}$ EVs, but the increasing energy capacity of the new vehicles is likely to cause more sparse probability of the charging events. Similarly, the probability of charging on public charging stations, not considered in this manuscript, is expected to reduce even more the loading on domestic feeders. Based on this knowledge, some EVs charge more times than others, as it would be expected in a real situation, and not every EV would charge when returning home.

The methodology is built upon Danish data, consisting of driving and departure/arrival time of the Danish population [34], and it is applied to a piece of distribution grid, to test and validate the proposed technique. The combination of the Japanese and Danish data is used to overcome the lack of real data of a whole society, and at the same time to provide a method for generating driving patterns which could be applied to other realities. Matlab is the considered tool for the EV charging load modelling, afterwards DIgSILENT PowerFactory is used to design the network and perform the load-flow studies.

This paper is organized as follows. The modeling of EV charging patterns is explained in Section II with a first introduction of the available data. Section III describes the tested case. The results are presented in Section IV and the paper is concluded in Section V.

\section{EV CHARGING LOAD MODELLING}

The model creates EV charging load profiles based on driving behaviour of car owners and plug-in ratio at home of the EVs. The model is built on the charging behaviour of gasoline car drivers, assuming that the users will drive the EVs with similar driving requirements. This hypothesis of study is due to the fact that the EVs battery capacity is increasing to fulfill the users demand, without need of changing in their everyday comfort and behaviour. The driving behaviour of car owners is provided by the Danish National Travel Survey [34]. The survey is based on 110000 interviews conducted in Denmark over the last 10 years. The data set describes the travelling of the interviewed people during the day the interview was conducted. In order to describe the behaviour of the privately owned 4-wheeled vehicles, the data set is sorted for people operating a vehicle and not just being a passenger, for which the daily distance driven, the leaving and arriving time are taken into consideration. The analysis represents the daily distance driven per privately owned car or van, not per person, which would be a lower number. Indeed in [35] the authors consider $39.5 \mathrm{~km}$ as daily traveling distance per person in Denmark, including all kinds of transport, whereas the average driving distance of cars is $45 \mathrm{~km}$ per day. Furthermore, the analysis of the Danish National Travel Survey showed that the car users drive less during the weekends than in the weekdays, with an average of $34.5 \mathrm{~km}$ on Saturdays and $32.9 \mathrm{~km}$ on Sundays. On top of that the use of the car is more distributed during the day hours, therefore a more distributed EV charging power contribution is expected during the weekends. Consequently, being the manuscript interest about the impact of $\mathrm{EV}$ penetration on the grid, the EV charging pattern during the weekends is assumed the same than in the weekdays. This is also possible considering that on Saturday and on Sunday the overall consumption is lower compared to the weekdays.

The charging probability is dependent on the human behaviour, which is affected by range anxiety due to vehicle range, available charging infrastructure, range requirements of drivers [36]-[40]. In the current model the probability of charging of the EVs is included as SOC and driving distance dependent, through the plug-in ratio at home of the EVs. This is the results of a Japanese study conducted by Nissan over 10000 EVs with $24 \mathrm{kWh}$ battery capacity. The data were collected by Nissan via the on-board telematic system in the vehicles during a period of one year.

\section{A. Parameters definition}

1) Group: The group number defines the distance driven per day by the vehicle. 10 groups are defined in Table I and the share of cars per group is shown in Fig. 1. The considered distribution of the daily distance driven per car represents the characteristic of the community in Bornholm, small Danish island located in the south of Sweden, which data are given by the Danish National Travel Survey. More info about Bornholm can be found in [41].

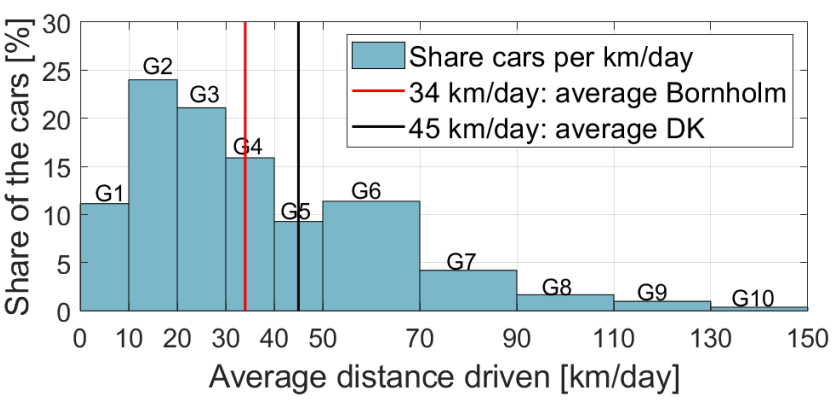

Fig. 1. Daily average driven distance per share of cars in Bornholm clustered into 10 groups.

TABLE I

GROUPS OF EVS CHARACTERIZED BY DRIVEN KM/DAY.

\begin{tabular}{cc|cc}
\hline Group & $\begin{array}{c}\text { Distance } \mathrm{x} \\
{[\mathrm{km} / \text { day }]}\end{array}$ & Group & $\begin{array}{c}\text { Distance } \mathrm{x} \\
{[\mathrm{km} / \text { day }]}\end{array}$ \\
\hline \hline G1 & $0<x \leq 10$ & G6 & $50<x \leq 70$ \\
G2 & $10<x \leq 20$ & G7 & $70<x \leq 90$ \\
G3 & $20<x \leq 30$ & G8 & $90<x \leq 110$ \\
G4 & $30<x \leq 40$ & G9 & $110<x \leq 130$ \\
G5 & $40<x \leq 50$ & G10 & $130<x \leq 150$ \\
\hline
\end{tabular}

2) Class: The class is defined from 1 to 10 and it represents the kilometres accumulated by the vehicle at the end of the day since the last charging, as reported in Table II. The class number can never be lower than the group number. 
TABLE II

CLASS CHARACTERIZATION.

\begin{tabular}{cc|cc}
\hline $\begin{array}{c}\text { Class } \\
\text { number }\end{array}$ & $\begin{array}{c}\text { accumulated } \\
\mathrm{km}\end{array}$ & $\begin{array}{c}\text { Class } \\
\text { number }\end{array}$ & $\begin{array}{c}\text { accumulated } \\
\mathrm{km}\end{array}$ \\
\hline \hline 1 & $0<x \leq 10$ & 6 & $50<x \leq 70$ \\
2 & $10<x \leq 20$ & 7 & $70<x \leq 90$ \\
3 & $20<x \leq 30$ & 8 & $90<x \leq 110$ \\
4 & $30<x \leq 40$ & 9 & $110<x \leq 130$ \\
5 & $40<x \leq 50$ & 10 & $130<x \leq 150$ \\
\hline
\end{tabular}

3) Category: At the end of each day, the EVs with the same group and class number are clustered into categories (cat).

4) State-of-charge: The state-of-charge (SOC) is the remaining capacity of the battery and it is evaluated in per unit (p.u.) as in (1):

$$
S O C(d)=Q(d) / Q_{n}
$$

$Q_{n}$ is the nominal capacity given by the manufacturer, the maximum amount of charge that can be stored in the battery, $Q(d)$ is the remaining capacity of the battery at the end of day $d$, before charging:

$$
\begin{gathered}
Q(d)=Q_{n}-Q_{u}(d) \\
Q_{u}(d)=x(d) * c+Q_{u}(d-1) \\
c=0.2 \mathrm{kWh} / \mathrm{km}
\end{gathered}
$$

$Q_{u}(d)$ is the used capacity and it depends on the driven kilometres on day $d$ and on the remaining capacity at the end of the previous day $d-1 . x(d)$ is the distance driven on day $d$. In this paper all the vehicles are assumed to have a $40 \mathrm{kWh}$ battery capacity, as the 2018 Nissan EV, with a range EPA of $240 \mathrm{~km}$. Such a size could represent the average storage of EVs in a near future, able to provide a large fraction of transportation needs in Denmark, as shown in Fig. 1. Also in cities with different driving habits, as for example investigated in [37]-[39], where the majority of the population does not drive more than $150-200 \mathrm{~km} /$ day, such storage value would be sufficient. Furthermore, considering that the EV battery capacity is going to increase in the future years, it is also expected an improvement of performance and capacity, with impact on the range anxiety and thus the proposed method would generate a slightly more conservative scenario. The average energy consumption $c$ is evaluated as ratio between the battery capacity and the average range distance of $200 \mathrm{~km}$, lower rounded from the range EPA for the Nissan EV 2018 of $240 \mathrm{~km}$, as conservative scenario. The EVs in the model are considered to be driven every day. If a vehicle is not charged it accumulates kilometres, meaning that if the vehicle did not charge on day $d-1$, the used capacity on day $d\left(Q_{u}(d)\right)$ is higher.

5) Plug-in rate at home: The Japanese statistics conducted by Nissan on $1000024 \mathrm{kWh}$ Nissan EVs derived the probability of charging at home of the commuters, based on the final SOC of the daily distance driven. Considering an individual user, the range anxiety is difficult to predict, because the users tend to charge their vehicles even when it is not necessary [36]. Differently, considering large groups of EVs, as done by
Nissan, it is possible to derive a relation between the plugin rate at home and the SOC, as reported in Fig. 2 with the curves obtained by performing curve fitting of the data set.

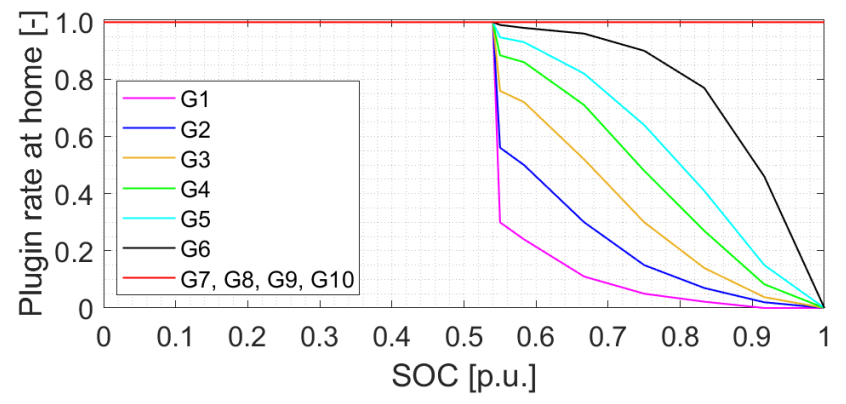

Fig. 2. Re-representation Japanese analysis: SOC - plug-in rate at home relation.

The first six lines represent groups G1-G6, they have different SOC for different rate of plug-in charging until $S O C=0.55$ p.u., for lower SOC they are very likely to charge. The red line represents the last four groups, which have the same behaviour, because in the Japanese analysis the plug-in rate was found to be very close to 1 , even with high values of SOC. Knowing the driven distance per day, the SOC of the EVs is determined with equations (1)-(3). Afterwards, knowing the SOC, the plug-in rate at home is evaluated for each group. In the Japanese study, due to the range anxiety factor, consumers that reach $S O C=0.55 \mathrm{p} . u$. are charging their vehicle almost every day. $S O C=0.55$ p.u. corresponds to $54 \mathrm{~km}$ :

$$
x_{24 k W h}=(1-0.55) * \frac{24 k W h}{0.2 k W h / k m}=54 \mathrm{~km}
$$

In this paper the Nissan EV has $40 \mathrm{kWh}$, larger capacity than the $24 \mathrm{kWh}$ considered in the study. Nevertheless, due to lack of data for EVs with similar capacities, as a conservative estimate, the EVs with SOC lower than 0.55 p.u. and $90 \mathrm{~km}$ of distance driven, are assumed to charge as well.

$$
x_{40 \mathrm{kWh}}=(1-0.55) * \frac{40 \mathrm{kWh}}{0.2 \mathrm{kWh} / \mathrm{km}}=90 \mathrm{~km}
$$

\section{B. Methodology description}

The model is described with a flow chart in Fig. 3. The inputs of the model are the number of EVs and the number of days to be simulated. The EVs are initially split into the 10 groups and characterized by a group number. On day $d$, the group and the class number of each EV is checked. At the beginning of the simulation all the EVs are considered fully charged $(S O C=1$ p.u. $)$, meaning that on day 1 , the class number of the EV matches the group number. An EV of G1 can have classes 1-7, but it never has classes 8-10, because when it accumulates maximum $90 \mathrm{~km}$ it is charged. An EV of G2 cannot be part of class 1, because it never accumulates less than $10 \mathrm{~km}$ since it never drives less than $10 \mathrm{~km} /$ day. A similar approach is applied to the other groups. The EVs, with same group and class numbers, are clustered into categories (cat). Using the curves in Fig. 2, for each category the rate of charging EVs is evaluated as ' $\% \mathrm{Y}$ ', and 
the distance accumulated by this group is thus reset to 0 (and $S O C=1$ p.u.). The remaining EVs do not charge ' $\% \mathrm{~N}$ ', so they accumulate kilometres. To create more variability on the distance accumulated, the no charging shares of EVs are split into 2 or 3 subgroups depending on the group number of the EV. The resulting groups characterization is reported in Table III. When all the categories $\mathrm{f}$ are entered in "charging probability loop", day d is completed and the simulation loop starts again with day $d+1$.



Fig. 3. Flow chart of the plug-in pattern model.

TABLE III

ACCUMULATED KM ON DAY D OF NOT CHARGING EVS, PER GROUP.

\begin{tabular}{cc|cc}
\hline Group & Accumulated km & Group & Accumulated km \\
\hline \hline \multirow{2}{*}{ G1 } & $50 \%$ EVs: $0-5 \mathrm{~km}$ & \multirow{2}{*}{ G4 } & $\begin{array}{l}50 \% \text { EVs: } 30-35 \mathrm{~km} \\
\text { 50\% EVs: } 5-10 \mathrm{~km}\end{array}$ \\
& $50 \%$ EVs: $35-40 \mathrm{~km}$ \\
\hline \multirow{2}{*}{ G2 } & $50 \%$ EVs: $15 \mathrm{~km}$ & \multirow{2}{*}{ G5 } & $50 \%$ EVs: $40-45 \mathrm{~km}$ \\
& $50 \%$ EVs: $15-20 \mathrm{~km}$ & & $50 \%$ EVs: $45-50 \mathrm{~km}$ \\
\hline \multirow{2}{*}{ G3 } & $50 \%$ EVs: $20-25 \mathrm{~km}$ & \multirow{2}{*}{ G6 } & $33 \%$ EVs: $50-55 \mathrm{~km}$ \\
& $50 \%$ EVs: $25-30 \mathrm{~km}$ & & EVs: $55-65 \mathrm{~km}$ \\
& & $33 \%$ EVs: $65-70 \mathrm{~km}$ \\
\hline
\end{tabular}

1) Model output: For every day of simulation each EV is characterized by a number and a letter:
- the number is the class of the EV at the end of the day

- the letter says if the EV is charging ' $\mathrm{Y}$ ' or not ' $N$ '.

\section{Charging time}

The described model defines the plug-in charging behaviour of the EVs. In this section the charging time is evaluated. Fig. 4 shows the share of arriving cars per each hour of a workday on Bornholm, known thanks to the Danish National Travel Survey. In general Danish commuters arrive at work at 7:009:00 and go back home between 16:00-19:00. The location of the arriving cars in Fig. 4 is unknown to the authors, but considering the Danish daily life it seems logical to assume that the arrivals from 16:00 to 19:00 represents the arriving at home. Therefore, considering the most conservative scenario, the authors assumed that the potential plug in events are split in 4 sets of 25\% EVs each: 16:00, 17:00, 18:00 and 19:00. This is the most conservative scenario, because the number of public chargers is increasing and in the future it is expected that more EV users will charge during the working hours [42]. The possibility of plug-in after 20:00 can be neglected, not only because the arriving cars after 20:00 are fewer in comparison to the rest, but also because the interest of the analysis is on the peak electricity consumption caused by the concurrency of domestic consumption and EV charging. The peak in the domestic consumption in Denmark is around 18:00, as in the example of Fig. 9.

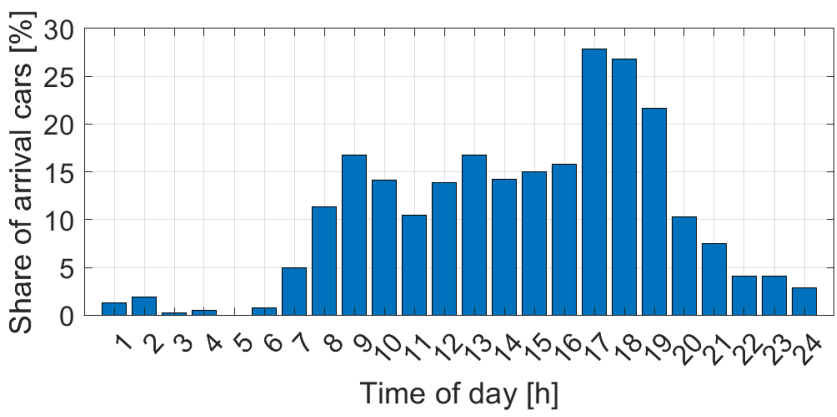

Fig. 4. Share of arriving cars per each hour of a workday on Bornholm. The sum of the shares is $200 \%$, due to the fact that the average number of trip per car is 2 per day.

It is assumed that the EVs can charge maximum once per day, as also done in [32], [43]. Furthermore, only private charging is considered. The charging time on day $\mathrm{d}(T(d))$ of an EV is calculated as in (7):

$$
\begin{aligned}
& T(d)=Q_{u}(d) / P_{\text {battery }} \\
& P_{\text {battery }}=P_{\text {charger }} * \eta
\end{aligned}
$$

with $Q_{u}(d)$ defined in (3), Pbattery is the power consumed by the battery as in (8), with $P_{\text {charger }}$ the rated power of the charger, as seen from the grid perspective, and $\eta$ the efficiency of the charger.

Most Danish households are supplied with three-phases and most EVs can charge with $16 \mathrm{~A}$ on one or three phases using the on-board charger. According to the IEC 61851 standard, in this manuscript the considered power rates are: $3.7 \mathrm{~kW}$ in single-phase (Ch-1ph) connection with $16 \mathrm{~A}$ and $230 \mathrm{~V}, 11$ 
$\mathrm{kW}$ in three-phase (Ch-3ph) connection with $16 \mathrm{~A}$ and $400 \mathrm{~V}$. At low power the Nissan EV can charge with constant power, even when the SOC is close to 1 p.u. [44]. For simplicity, in this manuscript also with three-phase chargers the EVs are charged at full power until $S O C=1$ p.u.. This is a conservative assumption, since in the reality the power consumption would decrease when the SOC is close to 1 p.u.. The onboard charger efficiency is found to be around 90\% [44], therefore the battery receives a power of $3.3 \mathrm{~kW}$ with singlephase chargers and $10 \mathrm{~kW}$ with three-phase chargers. When the EV is not charging or plugged-in but completely charged, the absorbed power is equal to zero. Table IV provides the charging time of the EVs in class 1-10 when single- and threephase chargers are considered. For the sake of simplicity the charging time per class is evaluated based on the maximum $\mathrm{km}$ of each range. This is a conservative but reasonable estimation because of the characteristics of the EV driving behaviour: EVs with the same initial characteristics that are driven for example $7 \mathrm{~km}$ and $10 \mathrm{~km}$ can have the same need of charging time, because of different driving styles.

TABLE IV

Charging TIME OF EVS IN CLASS 1-10 WITH SINGLE-PHASE ( $C h-1 p h)$ AND THREE-PHASE $(C h-3 p h)$ CHARGERS.

\begin{tabular}{|c|c|c|c|c|c|}
\cline { 5 - 6 } \multicolumn{1}{c|}{} & \multicolumn{3}{c|}{ Charge time [min] } & & \multicolumn{2}{c|}{ Charge time [min] } \\
\hline Class & Ch-1ph & Ch-3ph & Class & Ch-1ph & Ch-3ph \\
\hline $\mathbf{1}$ & 36 & 12 & $\mathbf{6}$ & 252 & 84 \\
\hline $\mathbf{2}$ & 72 & 24 & $\mathbf{7}$ & 324 & 108 \\
\hline $\mathbf{3}$ & 108 & 36 & $\mathbf{8}$ & 396 & 132 \\
\hline $\mathbf{4}$ & 144 & 48 & $\mathbf{9}$ & 468 & 156 \\
\hline $\mathbf{5}$ & 180 & 60 & $\mathbf{1 0}$ & 540 & 180 \\
\hline
\end{tabular}

The SOC of the EVs is unknown at the beginning of the simulation, thus all EVs are assumed to be fully charged ( $S O C=1$ p.u.). In a random day the EVs are expected to have differentiated SOC, therefore the Matlab code is run for two weeks (14 days), and the first week is disregarded. The considered scenario starts from day 1 of week 2 . If we have to randomize the initial distribution, several factors play an important role, specifically the choice of the initial SOC both in term of values and type of stochastic distribution. An incorrect randomization and initial SOC would inevitably compromise the quality of the first week of data. In this sense, the second week would be used anyway. Therefore, since it is necessary to create one representative week, the authors decided to train the model for one week and then choose the second one.

\section{Applied example: $20 \mathrm{EVs}$}

The model output is presented with an example of 20 EVs. The EVs are split into the 10 groups, but due to the low amount of EVs, only 7 groups are created. Table V shows the model output of the considered week 2 for the 20 EVs. Fig. 5 illustrates the charging loads of vehicles: 1 (G1), 8 (G3) and 16 (G5), highlighted with bold numbers in Table V. The black lines shows the results with single-phase chargers, the red lines with three-phase chargers. The vehicles plugin and charge the same amount of times during the week if using single- or three- phase chargers, the difference is on the charging duration and power consumption.

To verify that the generation process of the individual profiles is working correctly Fig. 6 is provided.

TABLE V

EXAMPLE OF PLUG-IN MODEL OUTPUT PER GROUP AND PER DAY FOR 20 EVS. THE ROWS SHOW THE VEHICLES AND THE RELATED GROUP THEY BELONG TO; THE COLUMNS SHOW THE VEHICLE CLASS AND WHETHER IS CHARGING (Y) OR NOT (N) ON THE SPECIFIC DAY.

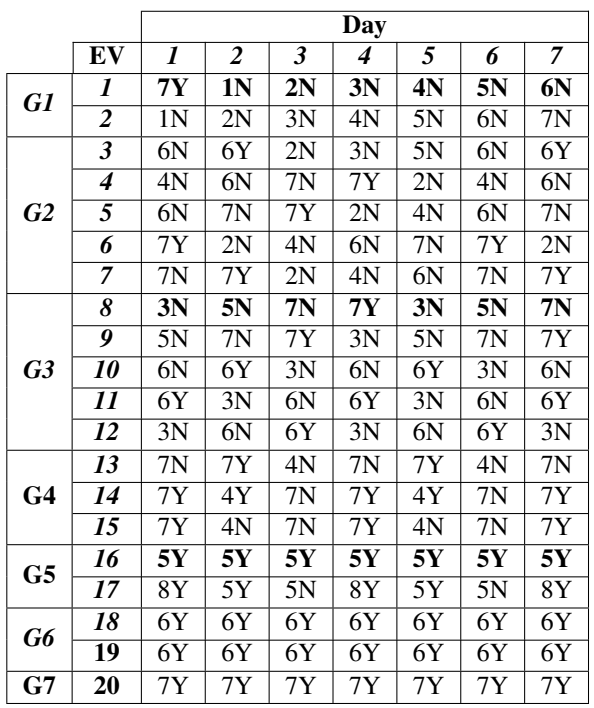
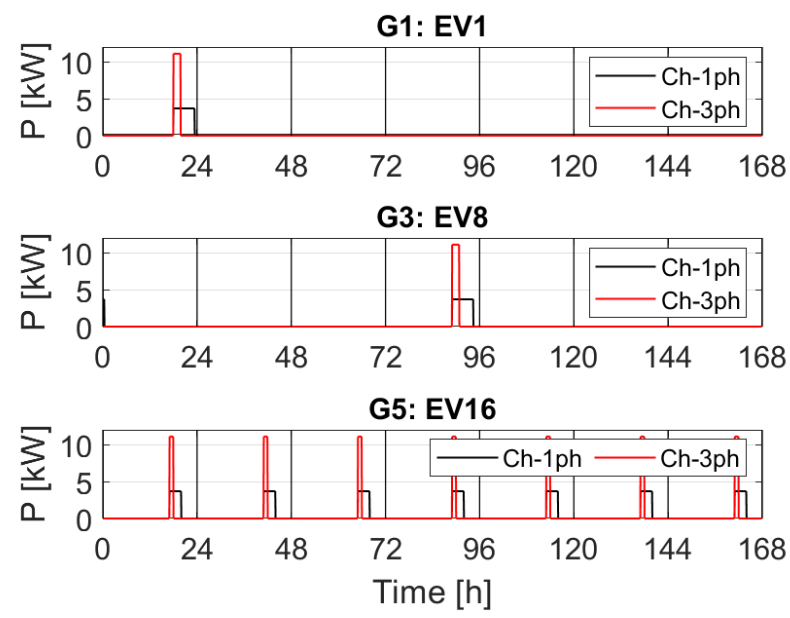

Fig. 5. Charging patterns of EV1, EV8, EV16 seen in Table V with singlephase (Ch-1ph) and three-phase (Ch-3ph) chargers.

Since the charging pattern model is used in this manuscript to create a relative small set of users (127 users, Section III), the distribution resemble given the initial distribution based on the $10000 \mathrm{EVs}$ from Japan is verified with three samples of EVs: 20, 127 and 1000. Fig. 6 subplot 1 shows that the smaller set of $20 \mathrm{EVs}$ does inevitably lead to discrepancies, since the plug-in rate at home has to be an integer value in the reality (we cannot charge half of a car). The situation is then improved for the case with 127 and finally with 1000 EVs in subplots 2 and 3. 

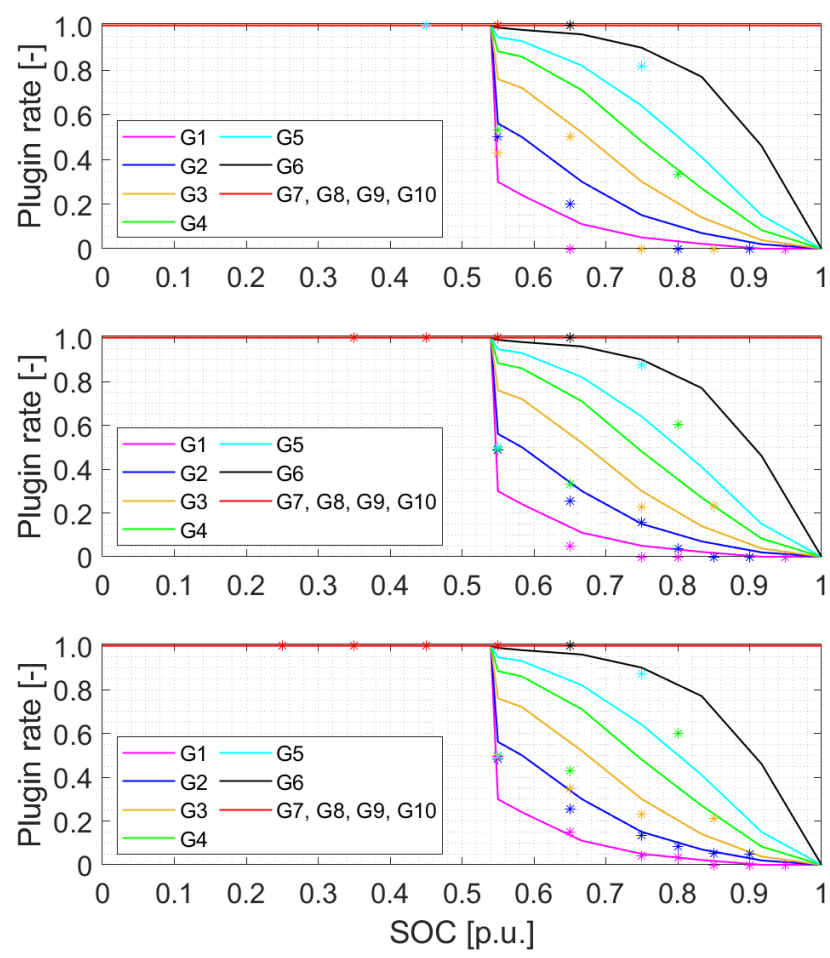

Fig. 6. The SOC - plug-in rate at home relations (line) are compared with the simulation data (markets): in subplot 1 with a sample of $20 \mathrm{EVs}$, in subplot 2 with a sample of 127 EVs and in in subplot 3 with a sample of 1000 EVs.

\section{GRID TEST CASE}

\section{A. Distribution Grid Characteristics}

The EV charging load model proposed in this paper has been applied to a radially run, semi-urban LV grid, based on a real network located in the Danish town of Tejn, Bornholm. The LV grid $(\mathrm{Un}=400 \mathrm{~V})$ is connected to the MV grid $(\mathrm{Un}=10 \mathrm{kV})$ through a $10 / 0.4 \mathrm{kV} 400 \mathrm{kVA}$ distribution transformer, see Fig. 7, and is supplied by under-ground cables with the technical characteristics shown in Table VI. The three bold types are the cables used at the beginning of the grid to connect the station (St. 29) with the first four terminals, whereas the rest of the feeders is composed of the different provided types. The grid consists of 4 feeders, with 127 users located as in Fig. 7.

TABLE VI

CABLE CHARACTERISTICS TEJN LV GRID. V AND I ARE THE RATED VOLTAGE AND CURRENT (GROUND), RESPECTIVELY. R' AND X' ARE THE RESISTANCES AND REACTANCES OF THE POSITIVE AND NEGATIVE SEQUENCE OF THE CABLES, R0 AND X0 ARE THE ZERO SEQUENCE COMPONENTS.

\begin{tabular}{ccccccc}
\hline Type & V $[\mathrm{kV}]$ & $\mathrm{I}[\mathrm{kA}]$ & $\mathrm{R}^{\prime}[\Omega / \mathrm{km}]$ & $\mathrm{X}^{\prime}[\Omega / \mathrm{km}]$ & $\mathrm{R} 0[\Omega / \mathrm{km}]$ & $\mathrm{X} 0[\Omega / \mathrm{km}]$ \\
\hline \hline 4x95 Al $^{*}$ & 0.4 & 0.235 & 0.320 & 0.069 & 1.280 & 0.276 \\
4x25 Al-M PEX & 0.4 & 0.100 & 0.866 & 0.086 & 3.462 & 0.344 \\
4x50 Al-M PEX & 0.4 & 0.155 & 0.640 & 0.079 & 2.57 & 0.314 \\
4x95 Al-M PEX & 0.4 & 0.235 & 0.320 & 0.075 & 1.280 & 0.302 \\
4x150 Al-M PEX ${ }^{* *}$ & 0.4 & 0.335 & 0.207 & 0.073 & 0.829 & 0.312 \\
4x16 Cu PVIIS & 0.4 & 0.100 & 1.150 & 0.089 & 4.610 & 0.358 \\
4x70 Cu PVIKS $^{* * *}$ & 0.4 & 0.230 & 0.269 & 0.082 & 1.070 & 0.329 \\
4x95 Cu PVIKS & 0.4 & 0.300 & 0.212 & 0.082 & 1.070 & 0.329 \\
\hline \hline
\end{tabular}

* Cable St. 29-Terminal 10058

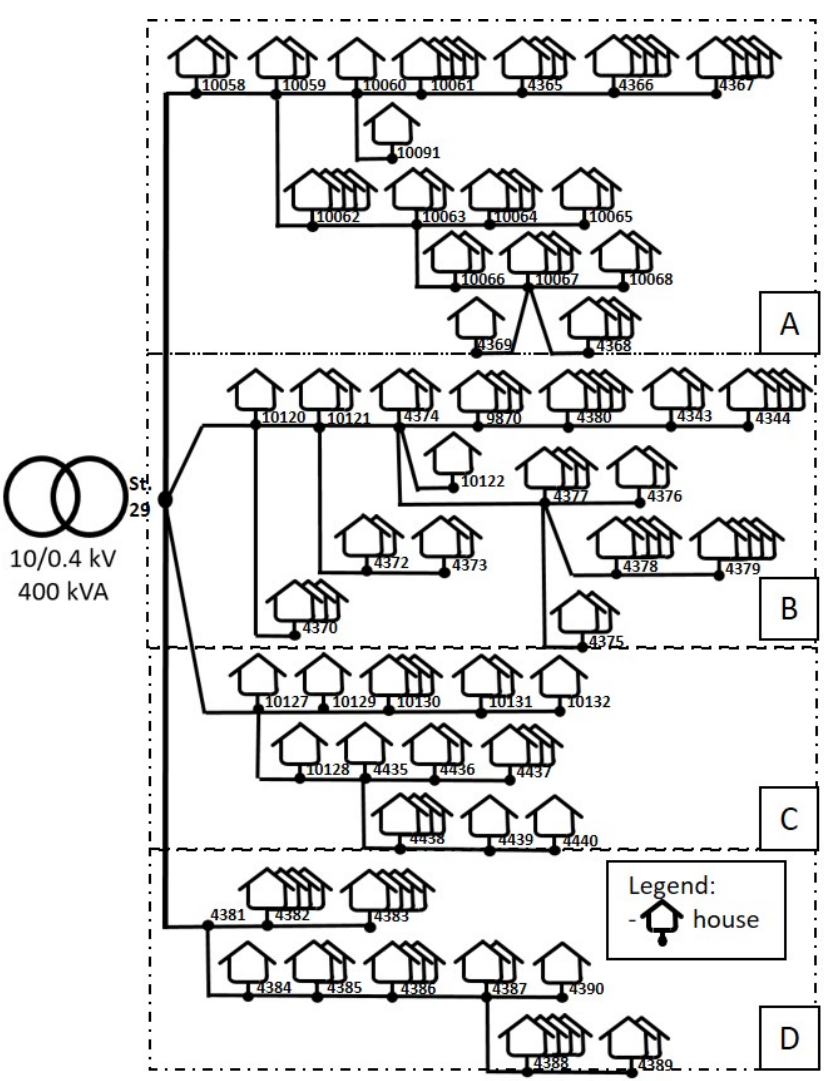

Fig. 7. Topology of simulated Tejn LV grid divided in four sub-feeders: A, $\mathrm{B}, \mathrm{C}$ and $\mathrm{D}$.

Thanks to the new smart meters under EU regulations, Bornholms Energi \& Forsyning (BEOF) provided individual active total consumption on 15 minutes basis. The data for all the households present in the considered grid are available to the authors for a one-week period. The considered week is week 9, from the 26th of February to the 4th of March 2018. During the week the temperatures were lower than the winter average ones, with values of $-10 /-15$ degrees, and since some of the houses have electric heating, the week consumption represents a bad case scenario. Accordingly with previous Danish grid investigations [45], analyzing the data of week 10 from the Smart Grid Unit (SGU) meters present at the transformer St. 29, the grid is found to be unbalanced. Fig. 8 provides the distribution of the current on the three phases, during one-week period. The first plot shows the currents on the three phases in ampere, whereas the second plot illustrates the percentage distribution of the currents on the three phases evaluated as in (9)-(10):

$$
\begin{gathered}
I_{t o t}=I_{a}+I_{b}+I_{c} \\
i_{a}=I_{a} / I_{t o t} \quad i_{b}=I_{b} / I_{t o t} \quad i_{c}=I_{c} / I_{t o t}
\end{gathered}
$$

Phase $a$ has higher loading compared to the others, and even though the share of unbalances varies during the week, the average share is found to be: $42 \%$ for phase a, $33 \%$ for phase $b$ and $25 \%$ for phase $c$. The maximum experienced unbalance is: $67 \%$ for phase a, $59 \%$ for phase $b$ and $60 \%$ for phase $c$. Consequently, the authors assumed to have: $40 \%$ of the measured three-phase load for each load in phase a, 30\% in 
phase $b$ and $30 \%$ in phase $c$. The SGU meters are firstly used to identify the unbalance between the three phases. Secondly the accuracy of the smart meters is verified by comparing the sum of all the smart meter active power consumptions with the SGU measured power. Nevertheless, the measurements at the transformer are not used during the load flow analysis, where only the smart meter data are considered as input of the simulations.

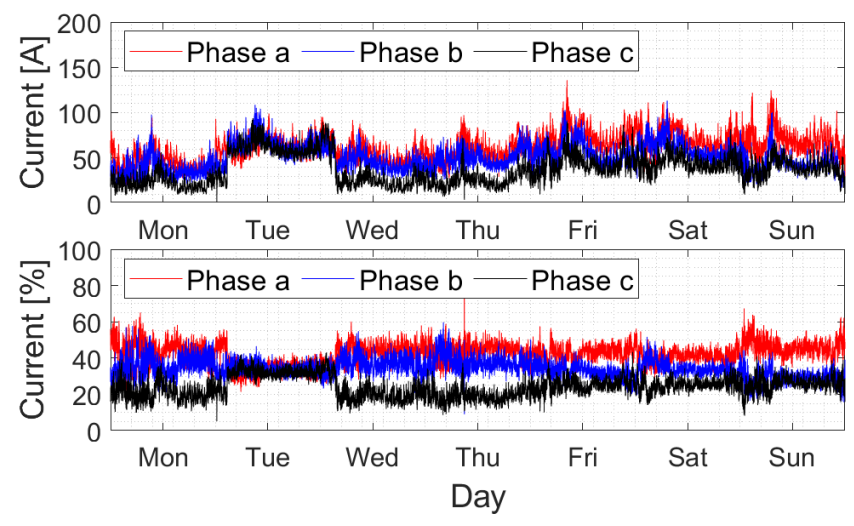

Fig. 8. Distribution of current on the three phases for a representative oneweek period: the first subplot shows the currents $I_{a}, I_{b}$ and $I_{c}$, the second subplot shows the percentage values of the currents $i_{a}, i_{b}$ and $i_{c}$.

Smart meters supply only active power data, thus to get the overall picture of the grid, with both active and reactive power flows, the latter information is needed. Thanks to the measurements provided by the EcoGrid project [46], active and reactive power consumption of 20 customers, supplied by the same transformer in Tejn, are provided and used to evaluate the average inductive power factor of 0.966 . This value is assumed as average for all the loads of the grid, to evaluate the reactive power consumption as function of active power and power factor.

The analyzed study case represents a typical LV distribution grid in Bornholm, making the results applicable to other distribution grids, at least, in Denmark. In the island there are $985 \mathrm{MV} / \mathrm{LV}$ transformers with an average nominal power of $240 \mathrm{kVA}$. With a total peak load of $60 \mathrm{MW}$, the average peak consumption of each transformer is circa $61 \mathrm{~kW}$. The ratio between the average peak consumption and the average nominal power is $0.25(61 \mathrm{~kW} / 240 \mathrm{kVA})$. The ratio in the analyzed transformer is 0.38 considering the studied week (150 kW as peak, without EVs). More details about model and technical evaluations can be found in [47].

\section{B. Electric Vehicles Integration}

EVs are included in the simulation considering alternatively single and three phase chargers. The charging loads applied to the modelled EVs are derived from the model described in Section II-B. All EVs are assumed to have $40 \mathrm{kWh}$ Lithiumion battery. With single-phase connection, the connections of the EVs are distributed sequentially on the three phases (33\% EVs per phase). With single-phase connection different penetration levels are investigated. The penetration of EVs is given as the average number of EVs per residential household, and since in Denmark there is an average of 1 car per house [34], 100\% EV penetration means that every household has an EV. With three-phase connection only the $100 \%$ penetration is investigated.

In both cases, with single- and three- phase connections, there is a linear dependency of the active power consumption of the $\mathrm{EVs}$ on the voltage measured at the connection terminal of the vehicle [24].

No reactive power is exchanged between the EV and the grid, as nowadays no commercial vehicle is capable of performing reactive power service. Due to the small amount of $200 \mathrm{VAr}$ drawn by the Nissan EV chargers, it can be assumed that reactive power consumed by EVs is negligible [48].

\section{RESULTS}

The analyzed scenarios are:

- Base case: current situation of the grid, without EVs, used as benchmark for the system.

- Single-phase chargers [25-100\% EVs]: single-phase uncontrolled charging with $4 \mathrm{EV}$ penetration levels: $25 \%$, $50 \%, 75 \%$ and $100 \%$.

- Comparison single- three- phase chargers [100\% EVs]: three-phase uncontrolled charging with $100 \%$ EV penetration level.

The analysis is focused on: transformer and cables loading, phase-to-neutral voltage and system losses. The phaseto-neutral voltage in Denmark is $230 \mathrm{~V}$. According to the European Standard, EN 50160 Voltage characteristics in Public Distribution Systems [49], the LV supply voltage must be within $10 \%$ of the nominal voltage value for $95 \%$ of the week at the point of delivery to the consumer, measured in 10 minute RMS values and it can never go below 0.85 p.u..

\section{A. Base case}

The current situation does not present under-voltage and congestion issues, see Fig. 9. Furthermore, the system losses are limited to $2-3 \%$ of the total consumption.

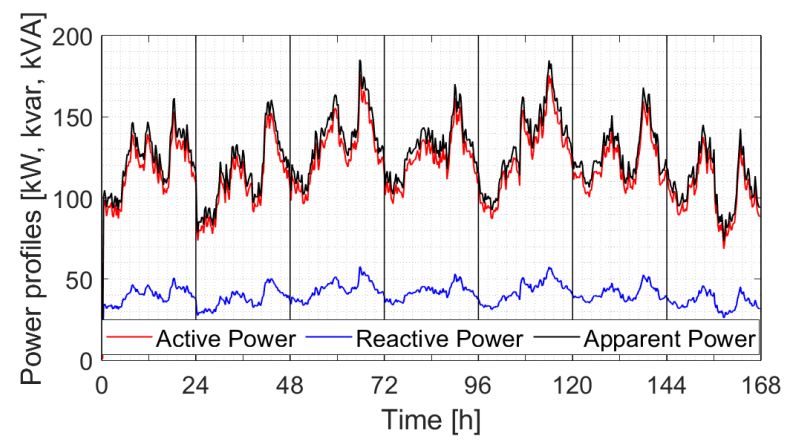

Fig. 9. Consumption profiles in the real Tejn LV grid week 9 2018, without EVs.

\section{B. Single-phase chargers [25-100\% EVs]}

A linear increase of transformer and cable loading is observed with the increment of the EV penetration level, however 
none of the components reach the $100 \%$ loading, see Fig. 10 . The system losses are observed to increase with a similar trend as the transformer and cable loading. Differently, the analysis of the voltage shows that the power system is more unbalanced and the voltage on the three phases are likely to present under-voltage values in the terminals farthest from the transformer station. Under-voltage outliers are observed from $50 \%$ penetration in Fig. 11, but within the limits of the EU standard.

The phase-to-neutral voltage magnitude is dependent on the location of the EVs on the phases. The initial condition of the grid was found to be already unbalanced. The EVs are equally distributed on the three phases, but the single phase connection and the differences between the charging patterns increase the unbalances in the most critical terminals, loading one phase more than the others. The phase-to neutral voltages are compared in Fig. 12 for the end-feeder terminals when $100 \% \mathrm{EV}$ penetration is implemented. The worst terminal 4379 is highlighted in the figure with bold lines.
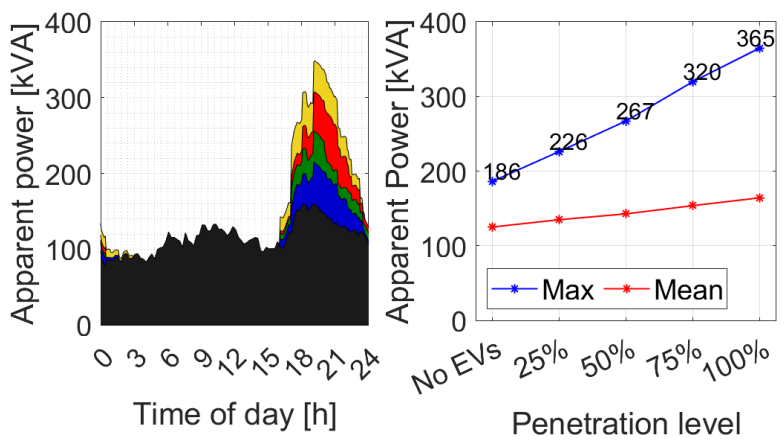

Fig. 10. Comparison transformer loading with $0 \%$ (No EVs), 25\%, 50\%, $75 \%, 100 \% \mathrm{EV}$ penetration levels: on the left one-day charging pattern, on the right one week values.

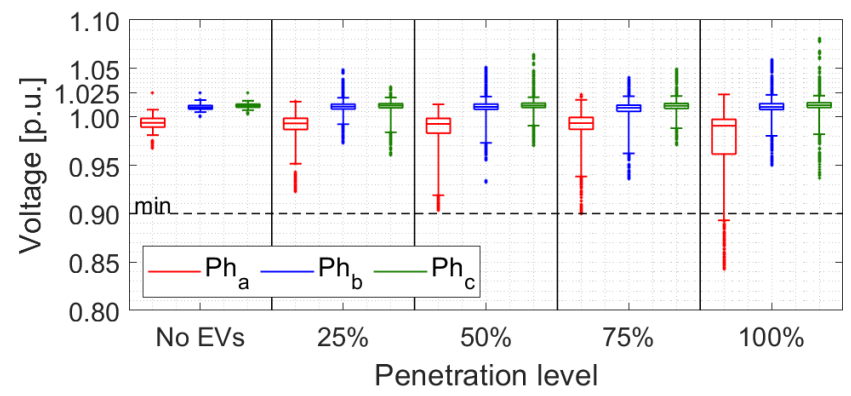

Fig. 11. Phase-to-neutral voltages for junction 4379 (end of feeder terminal) in the simulated grid during week 9.

Charging pattern probability equal to 1: The major contribution of the proposed model is the consideration of the charging pattern probability in the plug-in charging behaviour. Previous models in the literature present higher charging concurrent factors due to the lack of the probability factors. Fig. 13 shows the apparent power at the transformer level: the power gets higher compared to the values reported in Fig. 10 , reaching $456 \mathrm{kVA}$ in the $100 \%$ penetration. Fig. 14 shows that the phase-to-neutral voltages for junction 4379 present under-voltage from the $50 \%$ penetration level, and all values are more spread compared to the ones reported in Fig. 11. The maximum charging concurrent factor, reached during the peak time, is $56 \%$. Even though this value is lower than most of previous literature models, which depend on the specific driving characteristics considered, the concurrent charging would anyway result in grid issues at lower penetration levels.
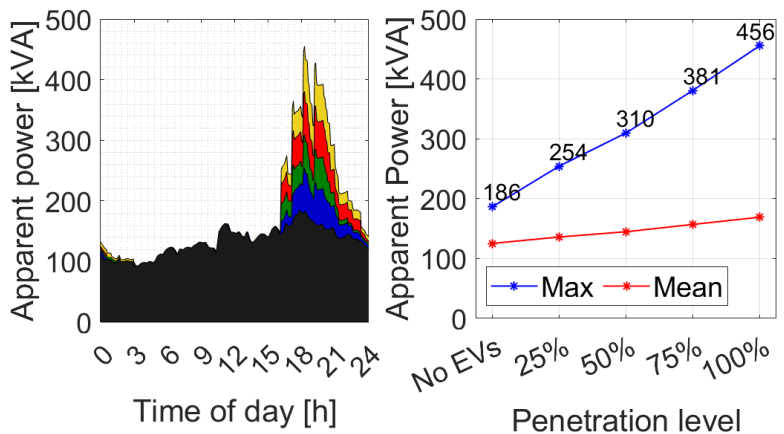

Fig. 13. Comparison of transformer loading with $0 \%$ (No EVs), 25\%, 50\%, $75 \%, 100 \% \mathrm{EV}$ penetration levels with charging probability equal to 1: on the left one-day charging pattern, on the right one-week values.

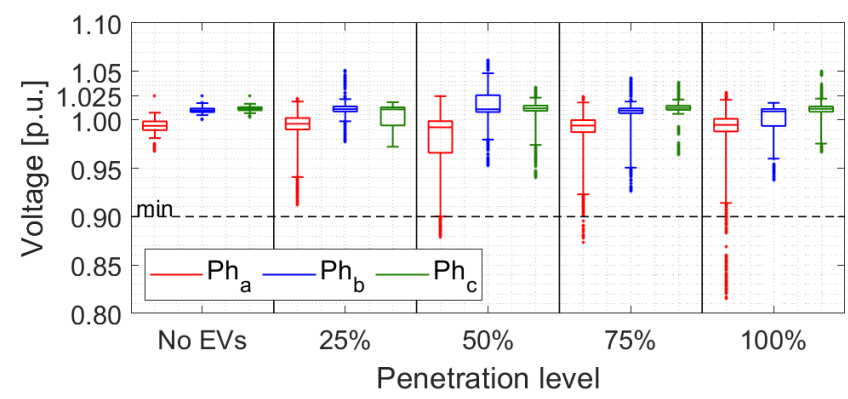

Fig. 14. Phase-to-neutral voltages for junction 4379 (end of feeder terminal) in the simulated grid during week 9 with charging probability equal to 1 .

\section{Comparison single- three-phase chargers [100\% EVs]}

Before analyzing the impact of the EV charging load on the grid, the comparison between the charging pattern with single- and three- phase chargers and $100 \% \mathrm{EV}$ penetration is observed in Fig. 15 for a one-day period.
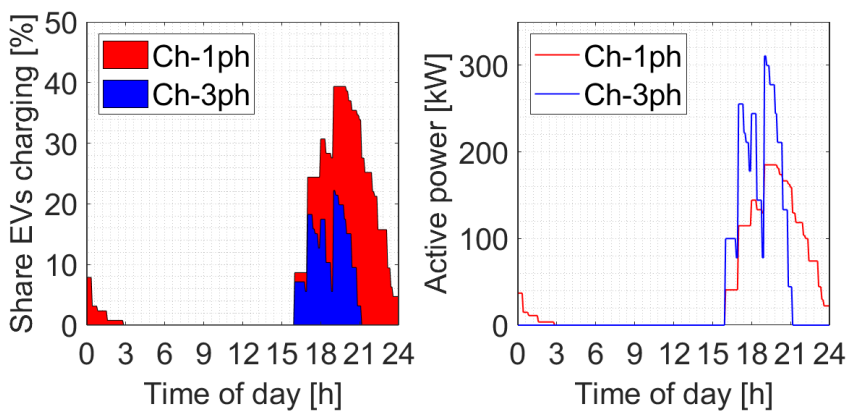

Fig. 15. Comparison single-phase and three-phase chargers: on the left the share of EVs charging and on the right the active power during one-day period.

It is found that, because most of the EVs does not need to charge every day, the simultaneous charging with singlephase chargers is never more than $45 \%$ EVs. Even though 


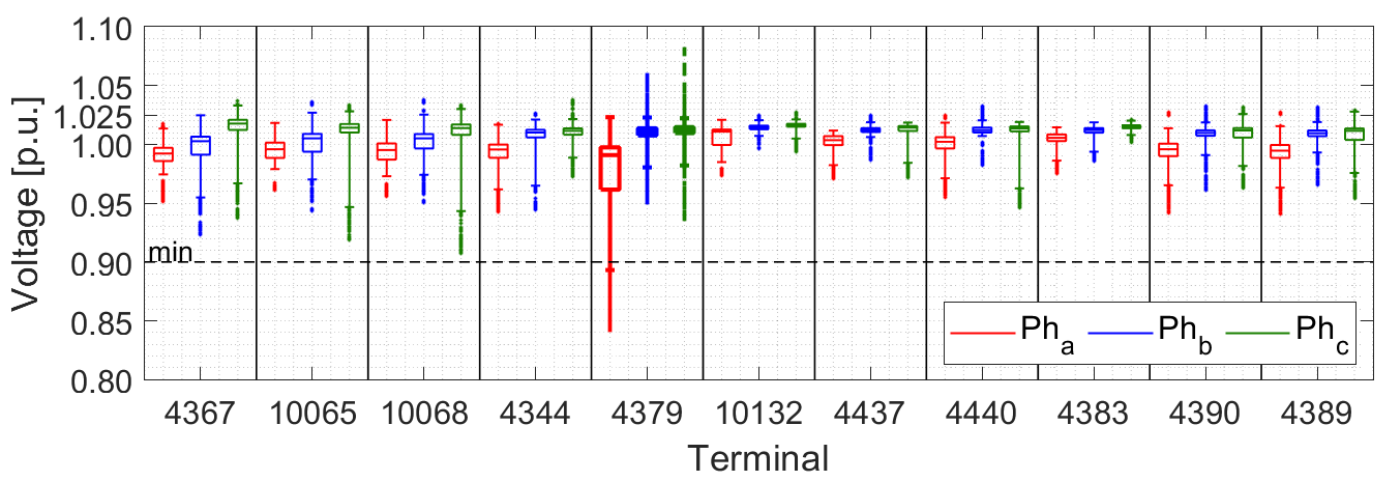

Fig. 12. Phase-to-neutral voltages for end-feeder terminals in the simulated grid during week 9 with $100 \%$ penetration level.

the energy consumption is the same, when using three-phase chargers the charging power is tripled, but the combined peak only increases to $50 \%$, because the simultaneous charging is reduced to $20-25 \%$. When the EVs are connected to the system with three-phase chargers the system is more balanced than with single-phase chargers, see Fig. 16.

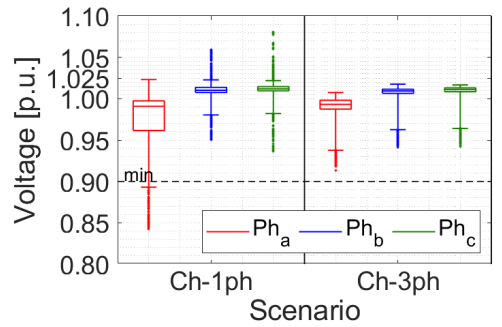

\begin{tabular}{|c|c|c|c|}
\cline { 2 - 4 } \multicolumn{1}{c|}{} & \multicolumn{3}{|c|}{ Transformer loading } \\
\cline { 2 - 4 } \multicolumn{1}{c|}{} & $\begin{array}{c}\text { mean } \\
{[\%]}\end{array}$ & $\begin{array}{c}\max \\
{[\%]}\end{array}$ & $\begin{array}{c}\text { time } \\
{[\mathrm{h}]}\end{array}$ \\
\hline Ch-1ph & 41.1 & 91.2 & 0 \\
\hline Ch-3ph & 40.8 & 120 & 9.25 \\
\hline & \multicolumn{4}{c|}{ Cable loading } \\
& St.29-10058 \\
\hline Ch-1ph & 35.5 & 86.9 & 0 \\
\hline Ch-3ph & 34.7 & 116 & 2.00 \\
\hline
\end{tabular}

Fig. 16. The figure shows: on the left the phase-to-neutral voltage for junction 4379 in the simulated grid during week 9: $100 \%$ penetration comparison; on the right the comparison mean, max and time period transformer and cable loading with single- and three- phase chargers.

On the contrary, transformer and cables are overloaded: the former for 9 hours, the latter for 2 hours. The most loaded cable is the one that connect the station to terminal 10058, see Fig. 7. Differently from the scenario with single-phase chargers, the system losses are here reduced, due to the more balanced distribution of the EV consumption on the threephases.

\section{Sensitivity analysis}

Two further investigations with the EVs connected in singlephase are also developed: the former highlights the consequences of different relocations of the charging patterns on the grid, the latter proves the importance of the equal distribution of the Evs on the three phases.

1) Charging pattern relocation: The sensitivity of the specific location of the charging patterns in the grid is analyzed diversifying the $\mathrm{EV}$ charging loads, which were initially placed in the grid in a random way (simulation $\alpha$ ), are also relocated with other two different displacements (simulations $\beta$ and $\gamma$ ) for each penetration level. The charging patterns, firstly created in Matlab, are displaced in the loads (EVs) of the different terminals in a uniformly randomized way for the three simulations. Fig. 17 shows the charging pattern of the aggregated EVs with $100 \%$ penetration in three representative terminals 10068,4379 and 4389 , but the same does work for the remaining EVs.
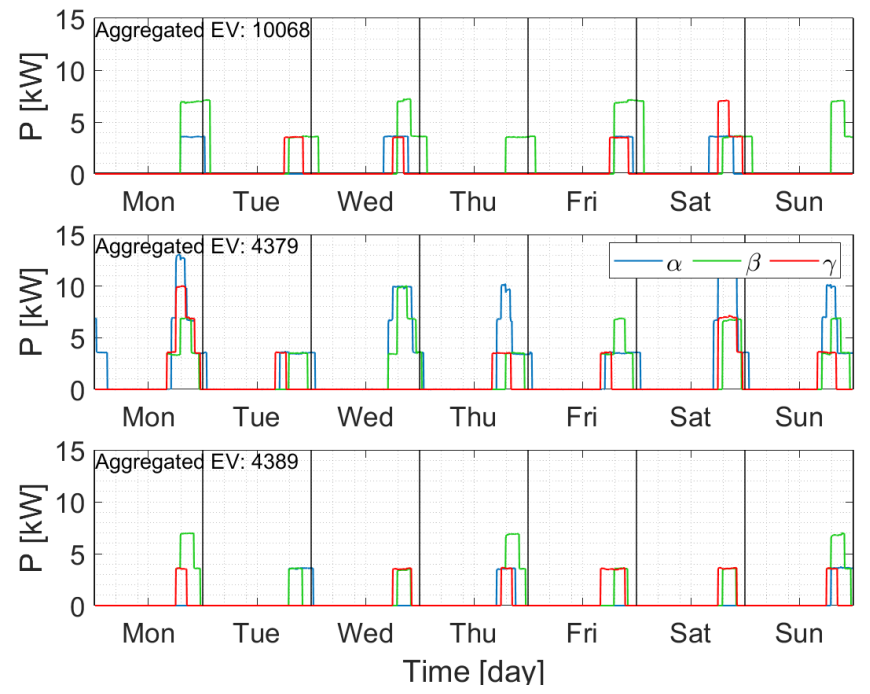

Fig. 17. Charging pattern of aggregated EVs terminals 10068, 4379 and 4389 for $100 \%$ penetration, simulations $\alpha, \beta, \gamma$.

It is found that the position of the EVs does not affect the congestion issues, indeed the maximum transformer loading is almost the same during the three simulations, see Fig. 18.

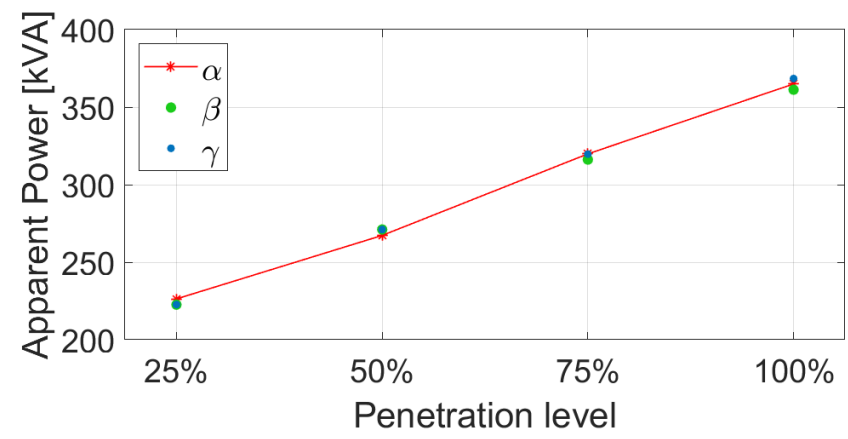

Fig. 18. The figure compares the maximum transformer loading of simulations $\alpha, \beta, \gamma$ from $25 \%$ to $100 \%$ penetration. 
The marginal difference is due to the amount of losses throughout the grid, since the charging power absorbed by all EVs is the same. Moreover, Fig. 19 and 20 show that the most critical terminal 4379 is the same for the three simulations, particularly for phase $a$. Firstly in Fig. 19 the phase to neutral voltage of phase $a$ is compared for the most critical terminal 4379. Secondly in Fig. 20 the voltage of three of the more loaded terminals is compared for the three simulations and the three phases.

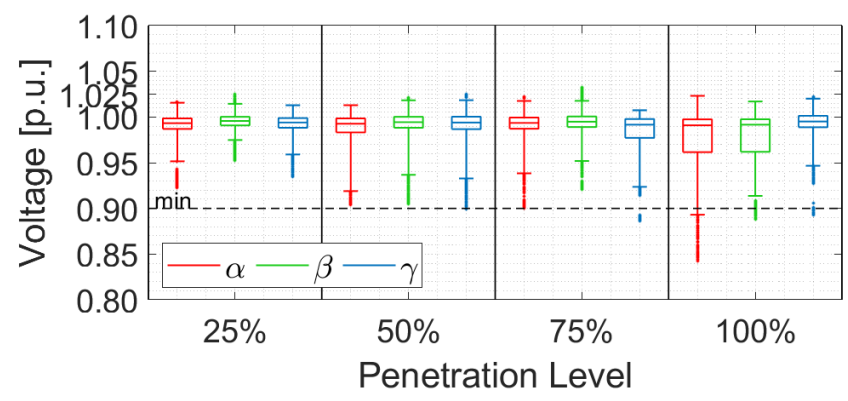

Fig. 19. The figure compares phase-to-neutral voltage of phase a for junction 4379 of simulations $\alpha, \beta, \gamma$ from $25 \%$ to $100 \%$ penetration.

2) Unbalanced distribution of the EVs on the three phases: The impact of single-phase chargers, with uneven distribution of the EVs on the three phases is analyzed implementing an unbalanced scenario. The EVs are here connected to the grid as follows: $50 \%$ in phase a, $25 \%$ in phase b and $25 \%$ in phase c (the EVs are distributed in a cycling way: 2 in phase a, 1 in $b, 1$ in c.). Fig. 21 shows that the new unbalanced scenario produces an increase of the voltage unbalances, and consequently of the losses, but the worst terminal is still terminal 4379. The transformer loading values are not provided because they are very close to the balanced scenario. Different is the situation for the most loaded cable: in the balanced scenario the most loaded cable is the one that connect St. 29 to terminal 10058, whereas in the unbalanced scenario it is the one connecting St. 29 to terminal 10120, see Fig. 21.

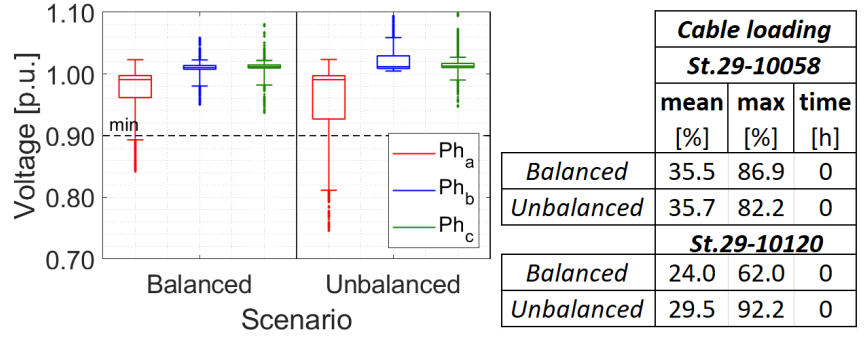

Fig. 21. The figure shows the comparison between the balanced and unbalanced scenarios: on the left the phase-to-neutral voltage for junction 4379 in the simulated grid, on the right the comparison mean, max and time period of the most loaded cables.

\section{CONCLUSION}

In this paper a method to generate individual EV charging patterns has been presented based on group characterization of the driving behaviour of private Danish vehicles and the SOC - plug-in at home ratio of EVs. Based on the input data, it was found that the possible loading caused by home charging of EVs is not as high as often estimated. Because most of the EVs does not need to charge every day, the simultaneous charging with single-phase chargers is never more than $45 \%$ EVs. Additionally, when using three-phase chargers the charging power is tripled, but the combined peak only increases with $50 \%$, because the simultaneous charging is reduced to $25 \%$. The proposed method shows that the impact on the grid of the EV charging load is expected to generate voltage unbalances when single-phase chargers are considered and transformer/cable overloading when three-phase chargers are instead implemented, because of the higher power value. It can be concluded that, in the short term with few EVs, the DSO should mainly focus on balancing the grid, because even though the EVs can be equally distributed between the three phases, the difference between the charging behaviour can aggravate the unbalances. On the contrary, in the long term, the large EV penetration with the growing electricity consumption could cause congestion issues as main problem in the distribution power systems. Most of the previous results, analyzed in Section I, highlighted a value of $30-50 \%$ penetration as maximum acceptable uncontrolled EVs charging, limitation caused by the simultaneous charging. In the current

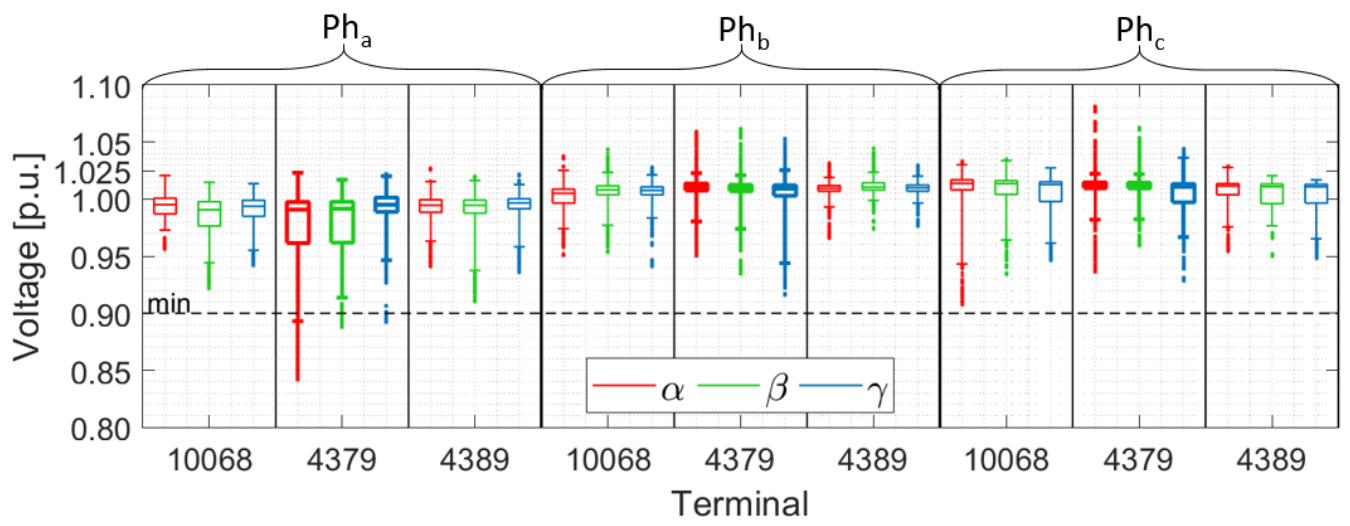

Fig. 20. The figure compares phase-to-neutral voltage of phase $\mathrm{a}, \mathrm{b}$ and $\mathrm{c}$ for junctions 10068, 4379 and 4389 of simulations $\alpha, \beta, \gamma$ with $100 \%$ penetration. 
manuscript it is shown that only a $100 \%$ penetration scenario initiates problems in terms of congestion. That is because it has been shown that simultaneous charging does not involve more than $45 \%$ of the users. Two different results that lead to a similar conclusion: the acceptable maximum share of charging EVs is approximately $30-50 \%$ depending on the grid characteristics, nevertheless the real penetration level can be actually higher.

It should be noted that the study results are system dependent, thus slightly different results may be obtained if considered other test feeders, nevertheless the method is generally applicable to different distribution networks. Furthermore, although there are no written rules on the maximum loading factor for transformers, it is common practice to consider a value equal to $70 \%$. The considerations made in the paper take the maximum load as $100 \%$, but if the $70 \%$ rule is enforced, a lower EV penetration scenario would be problematic with consequences on the transformer size choice [50].

Given the fast growth of public chargers in the past few years [42], future research should leverage the approach and data presented in this paper including public plug-in rate. For example the consideration of workplace chargers could affect the conclusions of the present study and further reduce the loading on the domestic distribution grids, decreasing the unbalances and congestion issues in the different scenarios and the necessity on finding ways of charging load control strategies. Furthermore, as future work the authors will assess how the multiple-objective use of the EVs, as grid based services, can affect the charging patterns determined by pure driving.

\section{ACKNOWLEDGMENT}

The work in this paper has been supported by the research projects ACES (EUDP grant nr: EUDP17-I-12499) and CAR (EU-Interreg grant nr: STHB.03.01.00-SE-S112/17). The authors would like to thank especially BEOF - Bornholms Energi and Forsyning A/S -, Nissan and DTU transport for providing most of the data used in this study.

\section{REFERENCES}

[1] Elnozahy MS, Salama MMA. A comprehensive study of the impacts of PHEVs on residential distribution networks. IEEE Trans Sustain Energy 2014;5:33242. doi:10.1109/TSTE.2013.2284573.

[2] Kong PY, Karagiannidis GK. Charging Schemes for Plug-In Hybrid Electric Vehicles in Smart Grid: A Survey. IEEE Access 2016;PP. doi:10.1016/j.jallcom.2014.03.093.

[3] Knezovic K. Active integration of electric vehicles in the distribution network - theory, modelling and practice. $\mathrm{PhD}$ Thesis, Technical University of Denmark, 2017.

[4] Marinelli M. The ACES Project - Large-scale Integration of Electric Vehicles into the Electric Power System. In Melero C, Mlhave K, editors, Sustain Conference 2018: Creating Technology for a Sustainable Society. Lyngby, Denmark: Technical University of Denmark (DTU). 2018. E-6.

[5] Energinet's analysis assumptions, REPORT. 2017.

[6] Knezovic K, Marinelli M, Zecchino A, Andersen PB, Traeholt C. Supporting involvement of electric vehicles in distribution grids: Lowering the barriers for a proactive integration. Energy 2017;134:45868. doi:10.1016/j.energy.2017.06.075.

[7] Haidar AMA, Muttaqi KM, Haque MH. Multistage time-variant electric vehicle load modelling for capturing accurate electric vehicle behaviour and electric vehicle impact on electricity distribution grids. IET Gener Transm Distrib 2015;9:270516. doi:10.1049/iet-gtd.2014.1019.
[8] Shahidinejad S, Filizadeh S, Bibeau E. Profile of charging load on the grid due to plug-in vehicles. IEEE Trans Smart Grid 2012;3:13541. doi:10.1109/TSG.2011.2165227.

[9] Shafiee S, Fotuhi-Firuzabad M, Rastegar M. Impacts of controlled and uncontrolled PHEV charging on distribution systems. 9th IET Int Conf Adv Power Syst Control Oper Manag (APSCOM 2012) 2012:154154. doi: $10.1049 /$ cp.2012.2160.

[10] Shao S, Pipattanasomporn M, Rahman S. Challenges of PHEV penetration to the residential distribution network. 2009 IEEE Power Energy Soc Gen Meet PES 09 2009:18. doi:10.1109/PES.2009.5275806.

[11] Schneider K, Gerkensmeyer C, Kintner-Meyer M, Fletcher R. Impact assessment of Plug-In Hybrid Vehicles on Pacific Northwest distribution systems. IEEE Power Energy Soc 2008 Gen Meet Convers Deliv Electr Energy 21st Century, PES 2008:16. doi:10.1109/PES.2008.4596392.

[12] Pieltain Fernndez L, Gmez San Romn T, Cossent R, Mateo Domingo C, Fras P. Assessment of the impact of plug-in electric vehicles on distribution networks. IEEE Trans Power Syst 2011;26:20613. doi:10.1109/TPWRS.2010.2049133.

[13] Gadea A, Marinelli M, Zecchino A. A market framework for enabling electric vehicles flexibility procurement at the distribution level considering grid constraints. 20th Power Syst Comput Conf PSCC 20182018. doi:10.23919/PSCC.2018.8443012.

[14] K. J. Dyke, N. Schofield, and M. Barnes, The impact of transport electrification on electrical networks. IEEE Trans. Ind. Electron., vol. 57, no. 12, pp. 39173926, 2010.

[15] J. A. P. Lopes, F. J. Soares and P. M. R. Almeida, Integration of Electric Vehicles in the Electric Power System. Proceeding of the IEEE, vol. 99, no. $1,2012$.

[16] C. K. Wen, J. C. Chen, J. H. Teng, and P. Ting, Decentralized plugin electric vehicle charging selection algorithm in power systems. IEEE Trans. Smart Grid, vol. 3, no. 4, pp. 17791789, 2012.

[17] Clement-Nyns K, Haesen E, Driesen J. The impact of Charging plugin hybrid electric vehicles on a residential distribution grid. IEEE Trans Power Syst 2010;25:37180. doi:10.1109/TPWRS.2009.2036481.

[18] Soares FJ, Lopes JAP, Almeida PMR. A stochastic model to simulate electric vehicles motion and quantify the energy required from the grid. 2011 17th Power Syst Comput Conf 2011:226.

[19] Abulawafa AR, Elagarably A, Mohamed WAF. Impacts of uncoordinated and coordinated integration of electric vehicles on distribution systems performance. 2017 19th Int Middle-East Power Syst Conf MEPCON 2017 - Proc 2018;2018February:33746. doi:10.1109/MEPCON.2017.8301203.

[20] Cundeva S, Mateska AK, Bollen MHJ. Hosting capacity of LV residential grid for uncoordinated ev charging. Proc Int Conf Harmon Qual Power, ICHQP 2018;2018May:15. doi:10.1109/ICHQP.2018.8378892.

[21] Hajebrahimi A, Kamwa I, Huneault M. A novel approach for plug-in electric vehicle planning and electricity load management in presence of a clean disruptive technology. Energy 2018;158:97585. doi:10.1016/j.energy.2018.06.085.

[22] Knezovic K, Soroudi A, Keane A, Marinelli M. Robust multi-objective PQ scheduling for electric vehicles in flexible unbalanced distribution grids. IET Gener Transm Distrib 2017;11:403140. doi:10.1049/ietgtd.2017.0309.

[23] Taylor J, Maitra A, Alexander M, Brooks D, Duvall M. Evaluation of the impact of plug-in electric vehicle loading on distribution system operations. 2009 IEEE Power Energy Soc Gen Meet PES 092009. doi:10.1109/PES.2009.5275317.

[24] Martinenas S, Knezovic K, Marinelli M. Management of Power Quality Issues in Low Voltage Networks Using Electric Vehicles: Experimental Validation. IEEE Trans Power Deliv 2017;32:9719. doi:10.1109/TPWRD.2016.2614582.

[25] Knezovic K, Martinenas S, Andersen PB, Zecchino A, Marinelli M. Enhancing the Role of Electric Vehicles in the Power Grid: Field Validation of Multiple Ancillary Services. IEEE Trans Transp Electrif 2017;3:2019. doi:10.1109/TTE.2016.2616864.

[26] Zhou B, Littler T, Meegahapola L, Zhang H. Power system steadystate analysis with large-scale electric vehicle integration. Energy 2016;115:289302. doi:10.1016/j.energy.2016.08.096.

[27] Ioakimidis CS, Thomas D, Rycerski P, Genikomsakis KN. Peak shaving and valley filling of power consumption profile in non-residential buildings using an electric vehicle parking lot. Energy 2018;148:14858. doi:10.1016/j.energy.2018.01.128.

[28] R. Abousleiman and R. Scholer, Smart Charging : System Design and Implementation for Interaction Between Plug-in Electric Vehicles and the Power Grid, IEEE Trans. Transp. Electrif., vol. 1, no. 1, pp. 1825, 2015.

[29] H. N. T. Nguyen, C. Zhang, and J. Zhang, Dynamic Demand Control of Electric Vehicles to Support Power Grid With High Penetration Level of 
Renewable Energy, IEEE Trans. Transp. Electrif., vol. 2, no. 1, pp. 6675, 2016.

[30] Muratori M, Moran MJ, Serra E, Rizzoni G. Highly-resolved modeling of personal transportation energy consumption in the United States. Energy 2013;58:16877. doi:10.1016/j.energy.2013.02.055.

[31] Muratori M. Impact of uncoordinated plug-in electric vehicle charging on residential power demand. Nat Energy 2018;3:193201. doi:10.1038/s41560-017-0074-z.

[32] Smart J, Schey S. Battery Electric Vehicle Driving and Charging Behavior Observed Early in The EV Project. SAE Int J Altern Powertrains 2012;1:2012-010199. doi:10.4271/2012-01-0199.

[33] Thingvad A, Marinelli M. Influence of V2G Frequency Services and Driving on Electric Vehicles Battery Degradation in the Nordic Countries Influence of V2G Frequency Services and Driving on Electric Vehicles Battery Degradation in the Nordic Countries. Evs31 2018.

[34] Hjalmar H. The Danish National Travel Survey. Lyngby, 2018.

[35] Thingvad A, Martinenas S, Andersen PB, Marinelli M, Olesen OJ, Christensen BE. Economic comparison of electric vehicles performing unidirectional and bidirectional frequency control in Denmark with practical validation. Proc - 2016 51st Int Univ Power Eng Conf UPEC 2016 2017;2017January:16. doi:10.1109/UPEC.2016.8113988.

[36] Faraj M, Basir O. Range anxiety reduction in battery-powered vehicles. 2016 IEEE Transp Electrif Conf Expo, ITEC 20162016. doi:10.1109/ITEC.2016.7520190.

[37] Shi X, Pan J, Wang H, Cai H. Battery Electric Vehicles: What is the Minimum Range Required? Energy 2018. doi:10.1016/j.energy.2018.10.056.

[38] Pearre NS, Kempton W, Guensler RL, Elango V V. Electric vehicles: How much range is required for a days driving? Transp Res Part C Emerg Technol 2011;19:117184. doi:10.1016/j.trc.2010.12.010.

[39] Dong J, Liu C, Lin Z. Charging infrastructure planning for promoting battery electric vehicles: An activity-based approach using multiday travel data. Transp Res Part C Emerg Technol 2014;38:4455. doi:10.1016/j.trc.2013.11.001.

[40] Khan M, Kockelman KM. Predicting the market potential of plug-in electric vehicles using multiday GPS data. Energy Policy 2012;46:22533. doi:10.1016/j.enpol.2012.03.055.

[41] J. Østergaard, J. E. Nielsen The Bornholm power system. An overview. Technical University of Denmark, May 2010.

[42] Nordic EV Outlook 2018 - Insights from leaders in electric mobility. International Energy Agency, 2018.

[43] Smart J, Powell W, Schey S. Extended Range Electric Vehicle Driving and Charging Behavior Observed Early in the EV Project. SAE Int J Altern Powertrains 2013;1:2013-011441. doi:10.4271/2013-01-1441.

[44] Kieldsen AH, Thingvad Nielsen AC, Sørensen TM, Jakobsen PM. Efficiency Test Method for Electric Vehicle Chargers. Proceedings of EVS29 - International Battery, Hybrid and Fuel Cell Electric Vehicle Symposium, 2016.

[45] Knezovic K, Marinelli M. Phase-wise enhanced voltage support from electric vehicles in a Danish low-voltage distribution grid. Electr Power Syst Res 2016;140:27483. doi:10.1016/j.epsr.2016.06.015.

[46] ECO-grid 2.0 project. http://www.ecogrid.dk (last access 1/10/2018/).

[47] Calearo L. Flexibility procurement by EVs in a Danish active distribution network: Study cases from the island of Bornholm. M.Sc. thesis in Sustainable Energy, DTU, Jun 2018.

[48] Rezkalla M, Zecchino A, Martinenas S, Prostejovsky AM, Marinelli M. Comparison between synthetic inertia and fast frequency containment control based on single phase EVs in a microgrid. Appl Energy 2018;210:76475. doi:10.1016/j.apenergy.2017.06.051.

[49] EN 50160:2010. Voltage characteristics of electricity supplied by public electricity networks. 2010.

[50] ipower consortium. Development of a dso-market on flexibility services. Report, 2013. 